based on exchange of military (armored) and.civilian ambulances; and (4) helicopter evacuation that is exclusively military. Civilian-military collaboration creates a combination of joined forces, fast response, and standards of work in the field and in hospitals. All can help reduce high mortality and morbidity due to MCIs. This work will present the areas of civilian-military collaboration in Israel and the advantages of this collaboration, based on past experience.

Keywords: civilian-military collaboration; Israel; mass-casualty incident; response

Prehosp Disast Med 2005;20(2):s85-s86

\section{Military-Civil Cooperation Issues in Disaster Medicine in Acts of Terrorism}

S. Goncharov

All-Russian Centre for Disaster Medicine, Russia

The concept of military-civil cooperation of the United Nations Office for the Coordination of Humanitarian Affairs (UN-OCHA) during an emergency was implemented. Particular attention was directed toward the control mechanisms used in the provision of emergency relief that was complicated by local military conflicts and acts of terrorism in Beslan. Stage I consisted of the collection and analysis of situational information, working out a plan of action, distribution of needs and deployment of human power and material resources with the interaction with the Ministry of the Russian Federation for Civil Defense, Emergencies and Elimination of Consequences of Natural Disasters (EMERCOM), and the Ministry of Internal Affairs, in response to the act of terrorism. Work in Stage I provided operational data from the situation, projection of the numbers of the injured, clarification of the general scheme for the medical-evacuation procedures, evacuation routes that could be used, the ambulance posts, and then management of prognosis of the injured. In addition, issues of medical triage and communication, the needs for evacuation transport, and informational support of the relief workers were identified.

During Stage II of the work, the conditions required for the admission of the injured to the republican hospital were prepared, and a pediatric field hospital was deployed that contained admission-triage, dressing, operational, and hospital-evacuation modules, as well as modules for support of the staff; all of the required processes for the "door-todoor" flows of injured/ill patients, and training of the responding medical personnel were prepared as well.

During Stage III, which continued for about four hours, the initial work with the injured was completed. "Door-todoor" triage was used to provide the required medical assistance and preparations were made for the urgent evacuation of many casualties to Vladikavkaz. A total of 120 beds for non-transportable and severely injured patients were reserved in the Central regional hospital. Every injured person was given about 1-7 minutes for triage and rendering immediate medical assistance. The main medical procedures were aimed at stopping internal and external hemor- rhages, at stopping asphyxia, normalizing breathing, and providing anti-shock measures. All severely injured children who couldn't be evacuated urgently underwent emergency surgery and resuscitation on-site.

During State IV, medical care was provided in the republican hospital of Vladikavkaz and the injured patients who required specialized medical care and follow-up treatment were prepared for air evacuation to medical institutions in Moscow and Rostov. During six days, there were 12 flights and 136 persons were evacuated-93 of them were children.

Keywords: air evacuation; children; disaster medicine; field hospital; military-civilian cooperation; response; Russia; terrorism Prehosp Disast Med 2005;20(2):s86

\section{Barents Rescue Exercise 2005-An Experience in Planning an International Arctic Search and Rescue Exercise Olaf Jacobsen; ${ }^{1}$ Raymond Teigen ${ }^{2}$ \\ 1. The Northern Norway Health Authorities, Norway \\ 2. The Northern Norway Health Authorities, Bodoe, Norway}

The Barents Rescue is a series of field training exercises organized and conducted by the countries of the Barents Euro-Arctic region. However, the exercise is open for international participation beyond the Barents region. It is an international field training exercise which focuses on challenges related to preparedness and emergency response in acute and serious crisis situations. It is an international challenge in weather-exposed and environmentally sensitive, remote areas in arctic waters. Particular emphasis is put on international, civil-military cooperation and interaction between the services from many countries that are mobilized in such situations. It gives practical, large-scale training for the whole trauma chain, including psychosocial work. The field training activities take place both at sea and on land.

The scenario evolves around crisis management after a terrorist attack on a large passenger vessel. The attack leaves a high number of casualties and a looming environmental threat at sea and along the coast. The scenario is developed in a manner that requires participation from many countries and numerous agencies and experts, such as rescue agencies, military, police, health, environmental agencies, and media experts.

As a part of the skill and competence building for trauma teams in the local rural hospital and key prehospital personnel in the Municipal Health Service, well-recognized practical trauma courses and lectures on triage, hypothermia, burns, and other selected themes open to all participants will be arranged.

The evaluation of the exercise, supported with existing knowledge about education, training, and lessons learned from similar exercises and real events, will contribute to the improvement of the international health response to disasters and other major events in the arctic region.

Keywords: Arctic; Barents Sea; cooperation; coordination; education; international

Prebosp Disast Med 2005;20(2):s86 